\title{
LA CERÁMICA A MANO CON DECORACIÓN DE BOTONES DE BRONCE: UNA APORTACIÓN AL ESTUDIO DE LA ALFARERÍA TARTÉSICA DEL BRONCE FINAL
}

\section{HAND-THROWN POTTERY WITH DECORATION OF BRONZE KNOBS: A CONTRIBUTION TO THE STUDY OF LATE BRONZE AGE TARTESSIAN POTTERY CRAFTMANSHIP}

\author{
por \\ MARIANO TORRES ORTIZ
}

\begin{abstract}
RESUMEN La cerámica a mano con decoración de botones de bronce es una de las producciones más características del Bronce Final (siglos X-VIII A.C.) del valle del Guadalquivir, definiendo un área cultural bien definida, tal vez reflejando un grupo étnico, y con una función determinada: servir de vajilla de mesa.
\end{abstract}

\begin{abstract}
Bronze knobs decorated pottery is one of the more characteristic productions of the Guadalquivir Valley's Late Bronze Age (X-VIII centuries). It depicts a well defined cultural area, maybe reflecting the edges of an ethnic group. It also has a clear use as a table ware.
\end{abstract}

Palabras claves Cerámica con decoración de botones de bronce, Bronce Final, Tartessos.

Key words $\quad$ Bronze knobs decorated pottery, Late Bronze Age, Tartessos.

\section{INTRODUCCIÓN}

Como contribución al homenaje al Prof. Pellicer, hemos elegido una clase cerámica sobre la que este investigador ha tratado en diferentes trabajos al analizar las producciones a mano del Bronce Final del Sudoeste Peninsular (Pellicer 1987-88: 473-474; Pellicer 1989: 179).

Aunque no ha tenido una especial relevancia en la investigación, dado que no se ha empezado a documentar hasta muy recientemente, esta clase cerámica constituye una de las más significativas del Bronce Final del valle Guadalquivir (Murillo 1994: 326-328; Lucas Pellicer 1995; Torres 1996: 150-151), principalmente en el área de la campiña cordobesa y el valle del Genil, donde se ha documentado el mayor número de hallazgos (fig. 1). 
Por ello, este elemento de cultura material pudo ser usado por estas poblaciones como un emblema étnico que las diferenciara de sus vecinas del bajo Guadalquivir, que se caracterizan sobre todo por el uso de las cerámicas de retícula bruñida y pintada de estilo Carambolo, y que pueden ayudarnos a delimitar diferentes territorios dentro del Bronce Final del valle del Guadalquivir, un período y un territorio que se puede caracterizar como plenamente tartésico.

\section{HISTORIA DE LA INVESTIGACIÓN}

La primera noticia sobre estas cerámicas parece ser la publicada por del Amo (1973: 389 fig. 4.1.) acerca de un fragmento con esta decoración hallado en el teatro romano de Medellín en un lote de material del Bronce Final hallado fuera de contexto, aunque este investigador no realiza ningún tipo de valoración sobre la misma.

Ya con posterioridad, se hallaron otros fragmentos en los estratos IIa y IIb del Cerro de la Encina (Arribas et alii 1974: 87, fig. 63:92) y en los túmulos A y B de Setefilla (Aubet 1975: 69, fig. 48:2; 1978: 34, fig. 20:2, 36, fig. 22:2; Torres 1996: 150-151).

Posteriormente, se produjeron nuevos hallazgos en el Cerro de los Infantes (Pachón, Carrasco y Pastor 1979: 316-317 fig. 14.2-4; Molina et alii 1983: 701 fig. 2:h), Belvís de la Jara, Toledo (Pereira 1989: fig. 3:5), el Cerro de la Miel (Carrasco, Pachón y Pastor 1985: 276-278 fig. 9:30), el Cerro de la Mora (Carrasco, Pachón y Aníbal 1986: 229 nota 160), el Llanete de los Moros (Baquedano 1987: 229 cuadro 1, 242-243), el Cerro Macareno (Pellicer 1987-88: 473), Vega de Santa Lucía (Murillo 1994: 96 fig. 4.31:435), La Saetilla (ibídem: fig. 4.72:2077), hallazgos de prospección del valle medio del Guadalquivir (ibídem: 327 fig. 5:66), Colina de los Quemados de Córdoba (Pellicer 1987-88: 473; 1989: 179; Murillo 1994: 210), en Camino Pucheros 1, Borox, Toledo (Muñoz López-Astilleros 1993: 329-330 fig. 7:12) y dos cremaciones del cerro de Alarcos (Lucas Pellicer 1995: 111, fig. 3:5; Muñoz López Astilleros 1999: 224).

Sin embargo, pocos son los estudios que han analizado el significado cultural de dichas cerámicas, entre los que destacan los trabajos de Molina, Pellicer y Lucas Pellicer.

Molina (1978: 219) cree que son de origen mediterráneo, aunque no postula ningún punto concreto de origen, desvinculándolas acertadamente de las cerámicas meseteñas con este tipo de decoración, más recientes cronológicamente.

Por su parte, Pellicer (1987-88: 474) señala sus orígenes remotos en el centro de Europa, aunque sus potenciales prototipos son casi todos cronológicamente posteriores a las producciones andaluzas y, en todo caso, no se percibe cual pudo ser su vía de difusión.

Por último, Lucas Pellicer (1995: 117-118) recoge también la vinculación de estas cerámicas con el centro de Europa, relacionándolas con la cultura de los Campos de Urnas y, posteriormente, con el mundo céltico. No obstante, la inexistencia de hallazgos en el Nordeste peninsular, la lleva a plantear la llegada por mar de esta técnica decorativa al Sudeste peninsular desde la península itálica, asociándola a la llegada de pequeños contingentes humanos.

\section{TIPOLOGÍA Y CRONOLOGÍA}

Hasta el momento, sólo se han documentado tres formas con esta decoración, dos de ellas de tradición del Bronce Final y una tercera que imita una forma bien conocida en el mundo fenicio. 
La primera forma es la típica cazuela carenada del Bronce Final precolonial (fig. 2.1). Por el momento, se conoce un ejemplar casi completo del Cerro de los Infantes (Mendoza et alii 1981: fig. 12:e; Molina et alii 1983: fig. 2:h).

La segunda forma es el vaso bicónico, en sus dos tamaños (fig. 2:2-3). Fragmentos pertenecientes a estos vasos se han hallado en el estrato XIII de Setefilla (Carrasco, Pastor y Pachón 1985: fig. 24:2), una urna y un pequeño vaso en el túmulo B de la necrópolis de este poblado (Aubet 1975: fig. 20:2, 22:2), otro vaso del Cerro de los Infantes (Pachón, Carrasco y Pastor 1979: 316-317 fig. 14.2-4), uno más del Cerro de la Miel (Carrasco, Pastor y Pachón 1985: fig. 9:30), un fragmento de carena y parte del hombro y la panza pertenecientes a un posible vaso de estas características de Medellín (del Amo 1973: 389 fig. 4.1.) y un gran vaso hallado en Alarcos (Lucas Pellicer 1995: fig. 3:5).

Por último, mencionar una pieza hallada en el enterramiento de la Casa del Carpio, Toledo (Pereira 1989: fig. 3:5), que imita la forma de un oinochoe de boca de seta fenicio (fig 2:4) que, por su tipología, podría fecharse en el siglo VIII A.C. (Ruiz Mata y Pérez 1995a: 56, 82 fig. 18:2).

En lo referente a su cronología, destacar que todas las piezas con esta decoración se documentan en contextos del Bronce Final precolonial, a excepción de las halladas en los túmulos A y B de Setefilla, en los que ya hay tumbas con importaciones fenicias, aunque ninguna asociada a estos vasos, y en el enterramiento de Belvís de la Jara.

Por ello, su fecha parece ser anterior al 700 A.C., según se desprende de la tipología de los platos fenicios de los túmulos A y B de Setefilla (Torres 1996: 151-152) y del ajuar funerario del enterramiento toledano (Torres 1999: 112).

En ese sentido, Molina (1978: 217,219) acertadamente atribuye estas cerámicas en el Sudeste a su Bronce Final II, etapa inmediatamente anterior a la aparición de las primeras importaciones fenicias, mientras que son demasiado recientes las fechas propuestas por Pellicer (1987-88: 474), que lleva estas cerámicas hasta el siglo VII A.C. basándose únicamente en los túmulos A y B de Setefilla, cuya cronología hemos reconsiderado recientemente (Torres 1996), y sin tener en consideración otros contextos.

\section{DISPERSIÓN}

Por el momento, el mayor número de hallazgos se concentra en el valle medio del Guadalquivir (fig. 1), valle del Genil y Vega de Granada (Murillo 1994: fig. 5:66), mientras que no se menciona su presencia en las prospecciones efectuadas en las provincias de Huelva, Cádiz y Sevilla, lo que parece confirmar que se trata de una decoración característica del Guadalquivir medio, estando localizado sus hallazgos más occidental hasta el momento en el Cerro Macareno y Setefilla.

Por otro lado, su aparición en Medellín, Alarcos y otros yacimientos de la Meseta Sur indica la existencia de vías de comunicación que atravesaban Sierra Morena y unían estas comarcas, tal como confirma la abundante presencia de estelas de guerrero en Córdoba (a ambos lados de Sierra Morena), Ciudad Real y Badajoz, que muestran además un estilo artístico muy similar, con una marcada tendencia al esquematismo y el recurso a la técnica del rebaje en los elementos representados (Celestino 2001: 88).

Todo ello, indica la existencia de un trasiego de objetos, gentes e ideas en estas comarcas ya desde el Bronce Final precolonial, dentro del marco de interacciones que se produce en el Sudoeste en este momento, aunque no creemos que se produzca un desplazamiento de población tan grande como defienden algunos autores, que sería precisamente el responsable de la introducción de las estelas de guerrero en el valle del Guadalquivir (Celestino 1998; 2001: 292 y ss.).

Por el momento, no nos atrevemos a hacer conjeturas sobre el nombre de esta etnia, aunque debemos considerarla como una de las que formaban parte de lo que las fuentes clásicas han denominado Tartessos. 


\section{CONTEXTO Y SIGNIFICADO}

Aparte de las piezas halladas en la necrópolis de Setefilla, en la tumba de Belvís de la Jara y la urna conteniendo una cremación de Alarcos, el resto de las piezas son hallazgos de superficie o encontradas en contextos domésticos.

Sin embargo, el que la redomita de Belvís de la Jara imite un jarro de boca de seta fenicio sugiere que esta decoración se usaba en piezas de cierto prestigio. Además, las formas documentadas incluyen grandes vasos bicónicos, copas de la misma forma y cuencos carenados, lo que sugiere la idea de un juego de vajilla compuesto por un gran contenedor para alimentos o líquidos (urnas), una copa para beber (vaso bicónico) y un recipiente para la comida (cuenco carenado).

\section{CONCLUSIONES}

De todo lo anteriormente expuesto se puede recapitular lo siguiente:

1. La ubicación dentro del Bronce Final (siglos X-IX A.C.) de esta clase cerámica, con perduraciones en los inicios de la Primera Edad del Hierro (siglo VIII A.C.), según se desprende de buena parte de los contextos en que se han hallado estas cerámicas.

2. El uso de esta cerámica como posible marcador étnico de las poblaciones del Bronce Final del valle medio del Guadalquivir, concentrándose principalmente en la actual provincia de Córdoba, en un espacio que se extiende aproximadamente al este del río Genil a lo largo de la Campiña.

3. Se trata, por tanto, de una cerámica de origen local, como demuestra su tipología, que usa una técnica decorativa determinada que existe en otras partes de Europa, pero sin tener vinculación directa con las mismas, explicándose la aparición de la misma técnica decorativa por convergencia cultural.

4. En lo referente a su funcionalidad, parece que nos encontramos ante una cerámica cuidada que, por su tipología, tiene principalmente un uso como vajilla de mesa fina.

\section{BIBLIOGRAFÍA}

DEL AMO, M. (1973): “Cerámica de "retícula bruñida" de Medellín”, XII Congreso Nacional de Arqueología. Jaén, 1971: 375-389. Zaragoza, Secretaria General de los Congresos Arqueológicos.

ARRIBAS, A.; PAREJA, E.; MOLINA, F.; ARTEAGA, O. y MOLINA FAJARDO, F. (1974): Excavaciones en el poblado de la Edad del Bronce "Cerro de la Encina" Monachil (Granada) (El corte estratigráfico $\left.n^{o} .3\right)$ (=Excavaciones Arqueológicas en España 81). Madrid, Ministerio de Educación y Ciencia.

AUBET, M ${ }^{\mathrm{a}}$.E. (1975): La necrópolis de Setefilla en Lora del Río, Sevilla. Barcelona, CSIC.

- (1978): La necrópolis de Setefilla (Túmulo B). Barcelona, CSIC.

BAQUEDANO, I. (1987): "Inicios del Bronce Final en la cuenca media del Guadalquivir: el Llanete de los Moros (Montoro, Córdoba)", Trabajos de Prehistoria 44: 223-250.

CARRASCO, J.; PACHÓN, J.A. y PASTOR, M. (1985): "Nuevos hallazgos en el conjunto arqueológico del cerro de la Mora. La espada de lengua de carpa y la fíbula de codo del Cerro de la Miel (Moraleda de Zafayona, Granada)", Cuadernos de Prehistoria de la Universidad de Granada 10: 265-333.

CELESTINO, S. (1998): "Los primeros contactos orientales con el suroeste de la Península Ibérica y la formación de Tartessos", J.-L. Cunchillos, J. M. Galán, J.-A. Zamora, S. Villanueva de Azcona (eds.), 
Actas del Congreso "El Mediterráneo en la Antigüedad: Oriente y Occidente", Sapanu. Publicaciones en Internet II (1998) [http://www.labherm.filol.csic.es].

(2001): Estelas de guerrero y estelas diademadas. Laprecolonización y formación del mundo tartésico. Barcelona, Bellaterra.

LUCAS PELLICER, Mª.R. (1995): “Cerámicas con apliques de metal”, Boletín de la Asociación Española de Amigos de la Arqueología 35: 107-122.

MENDOZA, A.; MOLINA, F.; ARTEAGA, O. y AGUAYO, P. (1981): "Cerro de los Infantes (Pinos Puente, Provinz Granada). Ein Beitrag zur Bronze- und Eisenzeit in Oberandalusien”, Madrider Mitteilungen 22: 171-210:

MOLINA,F. (1978): "Definición y sistematización del Bronce Tardío y Final en el sudeste de la Península Ibérica", Cuadernos de Prehistoria de la Universidad de Granada 3: 159-232.

MOLINA, F.; MENDOZA, A.; SÁEZ, L.; ARTEAGA, O.; AGUAYO, P. y ROCA, M. (1983): "Nuevas aportaciones para el estudio del origen de la cultura ibérica en la alta Andalucía. La campaña de 1980 en el Cerro de los Infantes", XVI Congreso Nacional de Arqueología, Murcia-Cartagena 1982: 689-707. Zaragoza, Secretaría General de los Congresos Arqueológicos Nacionales.

MUÑOZ LÓPEZ-ASTILLEROS, K. (1993): "El poblamiento desde el Calcolítico a la Primera Edad del Hierro en el valle medio del Guadalquivir", Complutum 4: 321-336.

- (1999): "Mirando al Suroeste de la Celtiberia: nuevos datos sobre la Primera Edad del Hierro en la cuenca media del Tajo". El origen del mundo celtibérico, ARENAS, J.A. y PALACIOS, Mª.V.(Coords.): 221-237. Molina de Aragón, Ayuntamiento de Molina de Aragón.

MURILLO,J.F. (1994): La Cultura Tartésica en el Guadalquivir Medio (=Ariadna 13-14). Córdoba, Iltre. Ayuntamiento de Palma del Río (Área de Cultura) y Excsma. Diputación Provincial de Córdoba (Área de Cultura).

PACHÓN, J.A.; CARRASCO, J. y PASTOR, M. (1979): "Protohistoria de la cuenca alta del Genil", Cuadernos de Prehistoria de la Universidad de Granada 4: 295-339.

PELLICER, M. (1987-88): "La cerámica a mano del Bronce reciente y del orientalizante en Andalucía occidental”, Habis 18-19: 461-483.

- (1989): "El Bronce Reciente y los inicios del Hierro en Andalucía occidental". Tartessos: arqueología protohistórica del bajo Guadalquivir, Aubet, $\mathrm{M}^{\mathrm{a}}$.E. (Coord.): 147-187. Sabadell: Ausa.

PEREIRA,J. (1989): "Nuevos datos para la valoración del hinterland tartésico. El enterramiento de la Casa del Carpio (Belvís de la Jara, Toledo)", Tartessos: Arqueología Protohistórica del Bajo Guadalquivir, AUBET, Ma..E. (coord.): 395-409. Sabadell, AUSA.

RUIZ MATA, D. y PÉREZ, C.J. (1995): El poblado fenicio del Castillo de Doña Blanca (El Puerto de Santa María, Cádiz). El Puerto de Santa María, Ayuntamiento de El Puerto de Santa María.

TORRES, M. (1996): "La cronología de los túmulos A y B de Setefilla. El origen del rito de la cremación en la cultura tartésica", Complutum 7: 147-162.

(1999): Sociedad y mundo funerario en Tartessos (=Bibliotheca Archaeologica Hispana 3). Madrid, Real Academia de la Historia. 


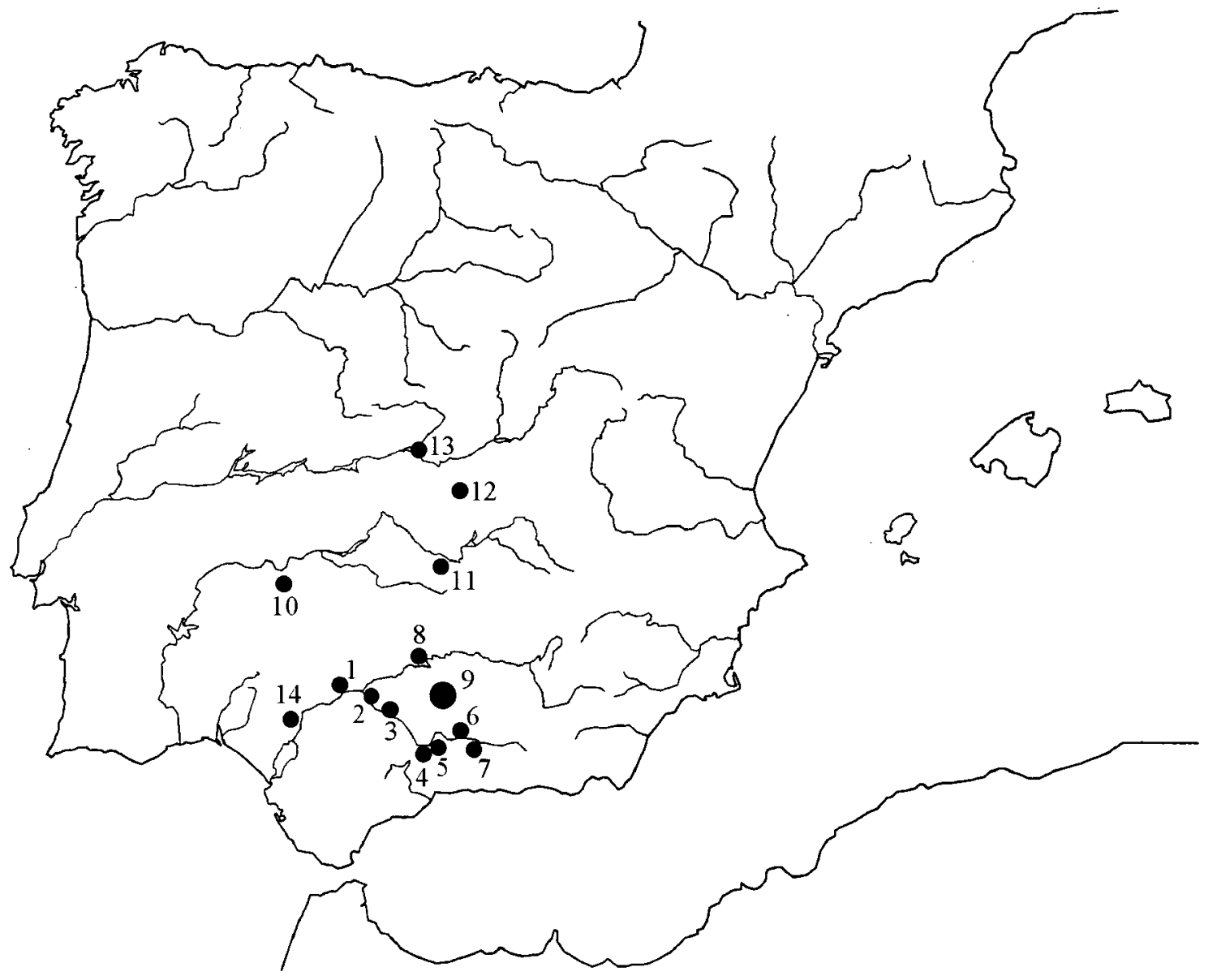

Figura 1: Dispersión de la cerámica con decoración de botones de bronce. 1. Setefilla; 2. La Saetilla; 3. Vega de Santa Lucía; 4. Cerro de la Mora; 5. Cerro de la Miel; 6. Cerro de los Infantes; 7. Cerro de la Encina; 8. Llanete de los Moros, Montoro; 9. Hallazgos de la campiña cordobesa; 10. Medellín; 11.Alarcos; 12. Camino Pucheros I, Borox; 13. Belvís de la Jara; 14. Cerro Macareno. 

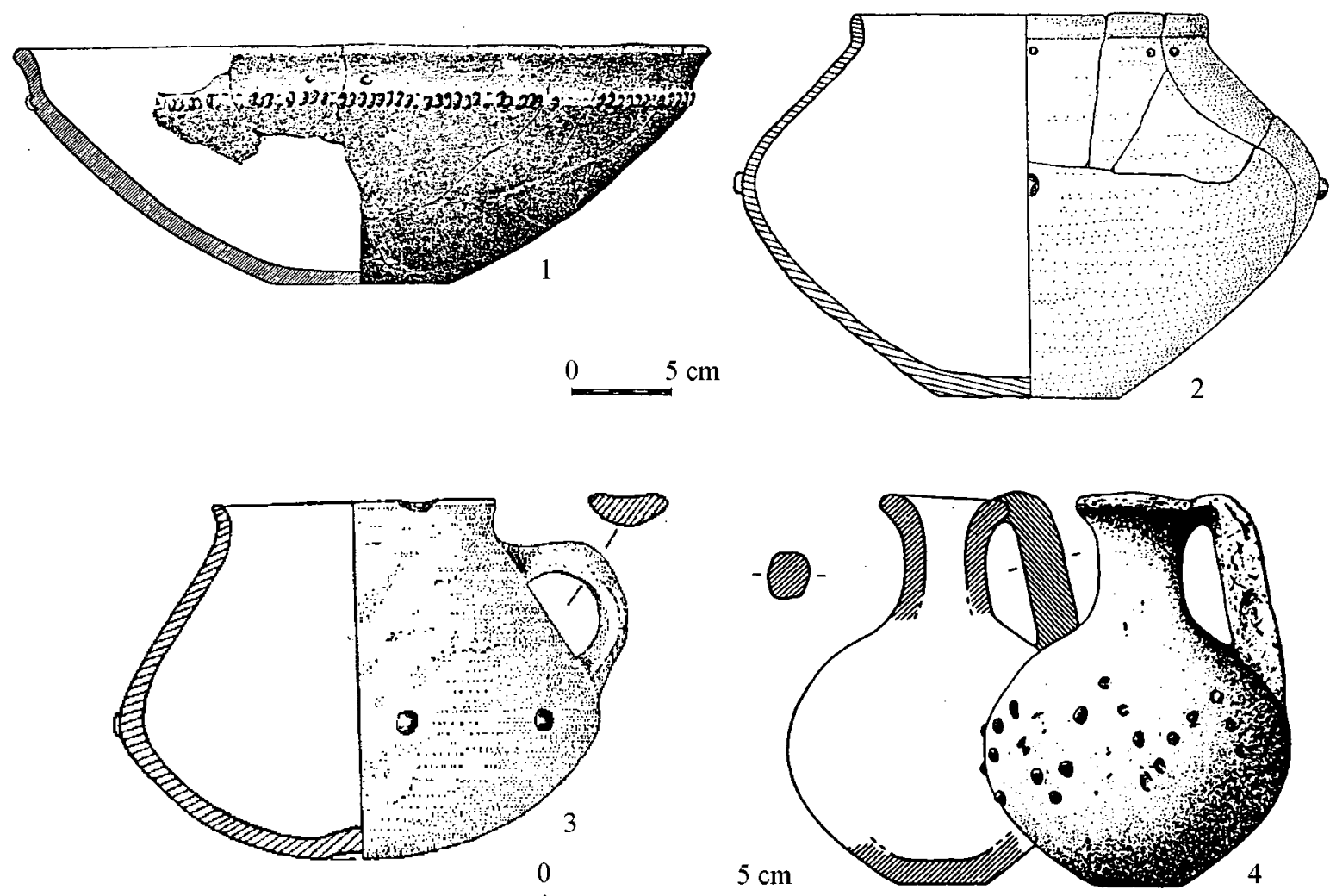

Figura 2: Tipología de la cerámica con decoración de botones de bronce. 1. Cuenco de carena alta (según Molina et alii 1983); 2. Urna bicónica (según Aubet 1978); 3. Taza de perfil bicónico (según Aubet 1978); 4. Imitación de oinochoe de boca de seta (según Pereira 1989). 